Archives

$30 \mid 2002$

Foccart - Entre France et Afrique

\title{
Jacques Foccart et les mauvais conseils de Félix Houphouët-Boigny
}

\section{Claude Wauthier}

\section{OpenEdition}

\section{Journals}

\section{Édition électronique}

URL : http://journals.openedition.org/ccrh/512

DOI : $10.4000 /$ ccrh.512

ISSN : 1760-7906

\section{Éditeur}

Centre de recherches historiques - EHESS

Édition imprimée

Date de publication : 30 octobre 2002

ISSN : 0990-9141

\section{Référence électronique}

Claude Wauthier, « Jacques Foccart et les mauvais conseils de Félix Houphouët-Boigny », Les Cahiers du Centre de Recherches Historiques [En ligne], 30 | 2002, mis en ligne le 22 novembre 2008, consulté le 20 avril 2019. URL : http://journals.openedition.org/ccrh/512 ; DOI : 10.4000/ccrh.512

Ce document a été généré automatiquement le 20 avril 2019

Article L.111-1 du Code de la propriété intellectuelle. 


\title{
Jacques Foccart et les mauvais conseils de Félix Houphouët-Boigny
}

\author{
Claude Wauthier
}

1 Un des premiers « faits d'armes", si l'on ose ainsi dire, de Jacques Foccart fut son soutien à la sécession du Katanga et à un dirigeant africain des plus douteux, Moïse Tschombé, auquel le général de Gaulle fit l'honneur d'être reçu à Paris en novembre 1964. Les éléments les moins recommandables des réseaux de Foccart, notamment du célèbre SAC (le service d'ordre gaulliste dont il fut l'un des animateurs) se retrouvèrent pour appuyer la sécession katangaise, qui fut ponctuée, on s'en souvient, par l'assassinat de Patrice Lumumba. Mais si l'on veut dresser un inventaire des conséquences de la présence de Jacques Foccart à l'Élysée et de l'orientation qu'il donna à la politique africaine de la France sous Charles de Gaulle, puis sous Georges Pompidou, il faut aussi se souvenir qu'il fut un grand ami du président ivoirien Félix Houphouët-Boigny. Jacques Foccart est sans aucun doute un de ceux qui ont le plus contribué à donner l'image de «vieux sage de l'Afrique » à un personnage dont l'influence se révéla pour le moins malencontreuse, à propos de la guerre du Biafra d'abord, puis en ce qui concerne les ventes d'armes au régime d'apartheid sud-africain.

2 Avant d'aborder ces deux cas de figure, il n'est peut-être pas sans intérêt de noter que Jacques Foccart est un de ceux qui ont aussi contribué à conforter l'image d'un Houphouët-Boigny dictateur tolérant, bon catholique, qui n'a jamais fait exécuter personne. Le conseiller du général de Gaulle pour les affaires africaines était pourtant un des Français les mieux placés pour savoir comment avaient été traités, humiliés et torturés - sous ses yeux dans sa résidence privée - les présumés comploteurs de 1963, dont l'ancien ministre Jean-Baptiste Mockey. Mais on sait qu'il a fallu attendre la parution, en 1997, du livre de l'un des « comploteurs », Samba Diarra, Les Faux Complots d'Houphouët-Boigny pour que ce triste chapitre de l'histoire d'Houphouët-Boigny soit révélé au grand public. Il faut dire que les meilleurs spécialistes de l'Afrique furent euxmêmes surpris, dont l'ancien journaliste du Monde, Philippe Decraene, qui fit d'ailleurs amende honorable de manière exemplaire dans une interview au journal ivoirien Le Jour, 
en reconnaissant très sincèrement que le livre de Samba Diarra lui avait ouvert les yeux. Et Decraene ajoutait, dans la même interview, qu'en comparaison, les "Mémoires de Foccart [n'étaient] qu'une parlotte $»^{1}$. C'était d'ailleurs l'impression de nombre de lecteurs : bien que pressé de questions par Philippe Gaillard - dont il convient de saluer ici la conscience professionnelle en même temps que la connaissance approfondie de l'Afrique francophone-Jacques Foccart avait refusé de s'expliquer sur des affaires auxquelles il serait curieux qu'il n'ait pas été « au parfum », pour reprendre une formule empruntée à la chronique de l'affaire Ben Barka. Ainsi apparaît donc Jacques Foccart, comme un homme secret et par essence "cachottier ", si ce terme à peine péjoratif peut convenir en la matière.

3 Mais les conséquences néfastes de la complicité entre le président Houphouët-Boigny et un Foccart décidé à fermer les yeux sur l'atroce répression du complot de 1963 en Côte d'Ivoire ne se limitent pas à ce mensonge par omission. Ce qui est plus important, c'est de constater que cette complicité entre les deux personnages a joué à plein dans les deux cas de figure évoqués plus haut, la guerre du Biafra et la vente d'armes à l'Afrique du Sud. On se souvient, en effet, que la Côte d'Ivoire fut l'un des plus fermes soutiens de la rébellion biafraise (avec le Gabon) et que ce soutien aboutit à faire durer une guerre civile cruelle qui fit près d'un à deux millions de morts: Jacques Foccart, Houphouët-Boigny et le général de Gaulle comptent avec Omar Bongo au nombre de ceux qui sont responsables de la prolongation d'une tuerie où les préoccupations politiques (affaiblir le géant anglophone d'Afrique noire qu'est le Nigeria) rejoignaient les intérêts économiques (Paris comptant y gagner des concessions pétrolières).

4 La fourniture d'armement à l'Afrique du Sud alors étroitement soumis à un apartheid rigoureux a permis à ce régime de survivre : grâce à la France qui lui a vendu Mirage, hélicoptères, blindés, sous-marins, frégates et le système de missiles sol-air Crotale. L'armée sud-africaine est ainsi devenue, et de très loin, la plus puissante du continent africain et pouvait considérer comme dérisoires les menaces des pays de la ligne de front (Mozambique, Angola, Botswana, Zambie, Tanzanie, puis Zimbabwe). On peut affirmer que le régime d'apartheid a pu se prolonger pendant des décennies grâce à la France du général de Gaulle : les Sud-Africains blancs ne s'y trompaient pas et rendaient volontiers hommage à l'homme du 18 juin. Et Houphouët, qu'en pensait-il ? Il avait imaginé de suggérer un "dialogue » avec l'Afrique du Sud pour la convaincre d'abandonner son système de ségrégation raciale. Il y avait même envoyé un de ses collaborateurs les plus proches, Laurent Donald Fologo en voyage officiel en 1975. C'était sans aucun doute une bonne manière qui faisait le jeu de Paris : au lieu de diaboliser le pays de l'apartheid, on l'invitait à une discussion qui lui conférait une meilleure image, et partant, il devenait moins scandaleux de lui vendre des armes. Ni le Journal de Jacques Foccart ni le livre de Pierre Péan, L'Homme de l'ombre, ne fournissent d'indications sur les sentiments que pouvait nourrir le conseiller du général de Gaulle sur ce commerce d'armes. Et aussi sur la coopération franco-sud-africaine dans le domaine nucléaire. Mais on peut penser qu'il était à l'unisson de quelques-uns de ses amis gaullistes, qui ne jugeaient pas d'un mauvais œil que Paris entretienne des relations amicales, et surtout fructueuses avec Pretoria. Et qui ne dédaignaient pas d'y aller faire du tourisme! En autre Pierre Messmer, dont l'épouse s'illustra en ramenant d'Afrique du Sud, en 1970, une collection de plumes d'autruche qu'elle exposa dans une galerie parisienne, ce qui lui valut quelques sarcasmes dans divers journaux parisiens. 
5 Il reste pour terminer ce portrait de l'un des hommes qui joua un rôle majeur dans la politique africaine de la France sous Charles de Gaulle et Georges Pompidou, à rappeler une de ses dernières interventions en public : lors du procès du mercenaire Bob Denard à Paris en 1999. Parmi les témoins de «moralité » qui vinrent faire l'éloge du mercenaire figurait Jacques Foccart (en bonne compagnie d'ailleurs avec le général Jeannou Lacaze et l'ancien ambassadeur au Gabon Maurice Delauney).

\section{NOTES}

1. Interview de Philippe Decraene, Le Jour, 10 et 11 mai, 1997. 